\title{
واقع إدارة الحدمات المصرفية الإلكترونية والتحديات * التي تواجهها في إقليم كوردستان العراق
}

دراسة استطلاعية لآراء عينة من موظفي بلموعة من المصارف العاملة في محافظة السليمانية

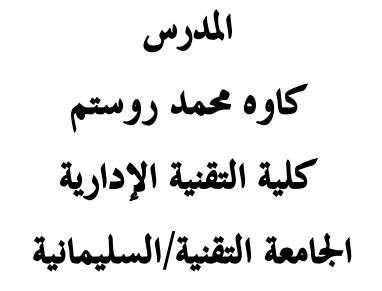

kawa.Rostam@uhd.edu.iq

\author{
المدرس المساعد \\ إبر اهيم مهدي عارف \\ كلية الادارة والاقتصاد \\ جامعة التنمية البشرية \\ ibrahim.arif@uhd.edu.iq
}

\section{المللخص:}

تهدف هذه الدراسة إلى التعرف على واقـع تطبيـق الحسـدمات المصـرفية الإلكتزونيـة لـدى لبنسوك العاملـة في محافظــة السليمانية، وذلك من كيفية إدارة هذه الحخدمات والصعوبات التي تواجه هذه البنوك في تطبيقها، وقـد قــام الباحثـان باسـتخدام المنهج الوصفي التحليلي في البحث، حيث تمثلت عينة الدراسة عدد من البنوك العاملة في محافظة السـليمانية والمتمثلـة في (بنـك هولير، بنك كوردستان الدولي، بنك دجلة والفرات، بنك الشمال، بنك الموصل) والتي بدأت بتطبيق هذه الخدمات لزبائنــها في محافظة السليمانية، وذلك من خحلال توزيع استمارة الاستبيان لهذا الغرض على المسوظفين في الإدارات العليـا والوسـطى والـدنيا متمثلة في( المدراء، ومسؤولي الشعب والوحدات والموظفين)، واستخدم الباحثان طريقة العينة العشوائية بتوزيع (07) اسـتبانة،

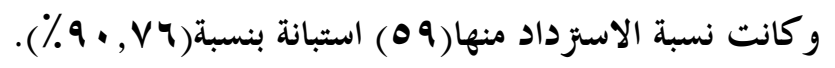
وقد خلصت الدراسة إلى أن هناك بدايات لنطبيق الخدمات الإلكتزونية لدى البنوك العاملة في محافظة السليمانية.

قدم هذا البحث في المؤتمر العلمي الدولي الرابع لجامعة التنمية البشرية/نيسان IV P . 
المقدمة:

تعتبر الحذدمات المصرفية من أحد أهم الأنشطة الاقتصادية، بحيث تدل درجة الطلب عليها على درجة التقـدم الاقتصـادي للبلـد

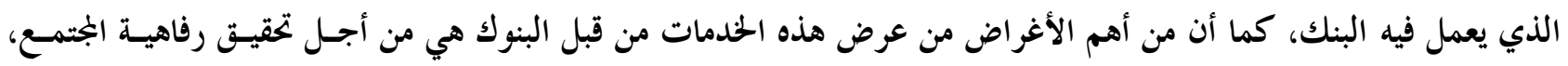

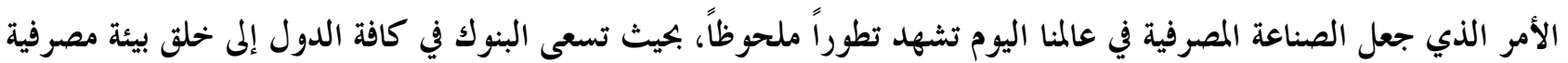
تجاوز تقليدتها، وذلك بالاستفادة من الثورة التكنولوجية والنظم المتطورة، ولعل من أبرز الأمور الـتي تريسد البنسوك اثباتها هـي الخروج من بيئتها التقليدية واستخدام وتقديم الحذدات المصرفية الإلكتزونية لعملائها بغية رفع المستوى الحذدي المصرفي وارتقائه من جهة، و الحصول على رضاء وتوسيع دائرة المتعاملين معها وزيادة القدرة التنافسية من جهة ثانية.

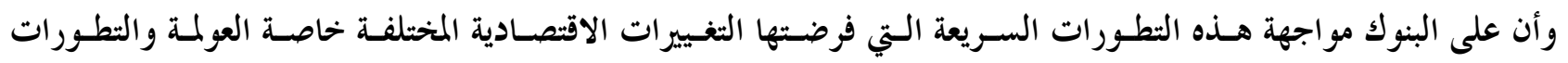
التكنولوجية في مجال الاعلام والاتصال، إلا أنه وعلى الرغم من وجود التطـور الهائسل في الحسدمات المصـرفية الإلكتزونيسة على الصعيد العالمي إلا أن استخدام هذه الحددمات في البنوك العاملة في العراق بشكل عام محدودة وضئيلة، ويأتي هذا البحث للوقوف

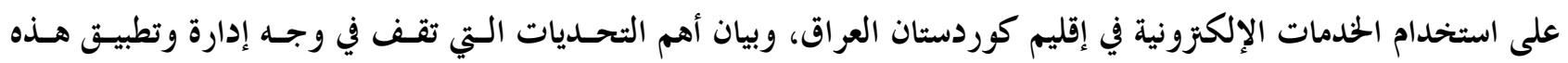
الحخدمات الإلكتزونية من خلال دراسة على مجموعة من البنوك العاملة في محافظة السليمانية. ويتكون هذا البحث من ثلاث محاور رئيسية، يناقش الخور الأول تحديد مفهوم الخدمات المصرفية الإلكتزونية وأهميتها وأنواعها، والخور الثاني إدارة الخدمات المصرفية الإلكتزونية والتحديات التي تواجهها، والخور الأخير هو الجانب العملي الذي يبحث واقع تطبيق هذه الحخدمات في المصارف العاملة وبيان أهم التحديات التي تقف أمام إدارة وتطبيق هذه الحخدمات الإلكتزونيـة، بـالتطبيق على مجموعة من البنوك في محافظة السليمانية. وينتهي البحث بمجموعة من النتائج والوصايا التي تطرح فيه أهم سبل معالجة التحديات الموجودة.

\section{أولاً: مشكلة البحث:}

على الرغم من التطور الكبير في مجال تقديم الحدمات المصرفية عالمياً، إلا أن هناك قصوراً واضحاً في استخدام هذه الحسدمات في البنوك العاملة في الإقليم، فعند زيارات الباحثين الميدانية ولقائهما بعديد من الزبائن والمتعاملين والمـوظفين تـبين لممـا بـأن غالبيـة البنوك لا تعتمد الخدمات الإلكترونية في انجاز الحذدمة المصرفية، وأن استخدام هذه الحخدمات في البنوك محل الدراسة تعتمد آليات

وأشكال بسيطة في الحخدمة الإلكتزونية. إزاء ذلك تكمن مشكلة البحث في بيان أهم الصعوبات والتحديات التي تقف أمام تطبيق هـذه الحــدمات في البــوك العاملـة في الإقليم وخحاصة في محافظة السليمانية. 
ثانياً: أهمية البحث:

تأتي أهمية البحث في وجود التطورات الهائلة التي شهدتها القطاع المصرفي على الصعيد العالمي في استخدام التكنولوجيـا لتقـديم

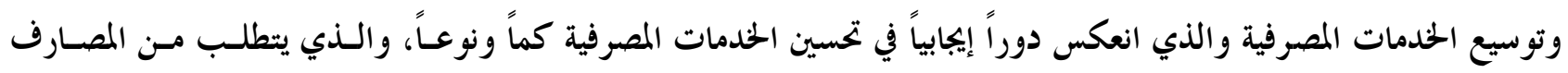
العاملة في الإقليم ادخال هذه الحذدمات المصرفية من خلال التوجه نحو الصيرفة الإلكتزونية. وعليه جاء هذا البحث للوقوف على أهمية تطبيق الحذدمات الإلكتزونية المصرفية في محافظة السليمانية وبيان أهـم طـرق إدارتهـا والتحديات التي تقف في وجهها بغية تقديم الحلول الواقعية والممكنة لتجاوز هذه التحديات من أجل تطبيق هذه الحـدمات الـتي أصبحت اليوم ضرورية من قبل البنوك العاملة.

ثالثاً: أهداف البحث:

يهدف هذا البحث إلى:

التعرف على مفهوم الحدمات الإلكنزونية المصرفية وبيان أهميتها وأنواعها. معرفة واقع مستوى الحخدمات المصرفية الإلكزونية في الإقليم.

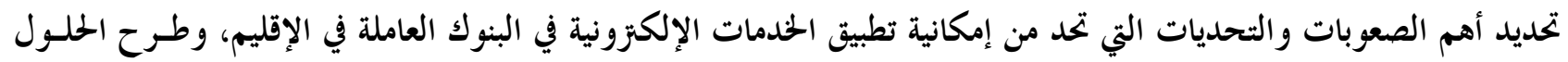
الممكنة لها.

\section{رابعاً: فرضية البحث:}

للإجابة على مشكلة البحث وقصد تسهيل الإجابة على مشكلته، نعتمد فرضيتين أساسيتين:

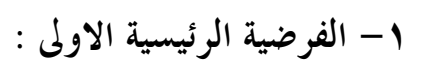

أ. فرضية الفرض والذي نصه (تو جد علاقة ذات دلالة احصائية بين إدارة الحدمات الإلكتزونية ومعوقات تطبيقها). ب. فرضية البديل والذي نصه (لا توجد علاقة ذات دلالة احصائية بين إدارة الخدمات الإلكنزونية ومعوقات الكات تطبيقها).

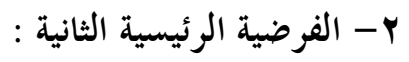

أ. فرضية الفرض والذي نصه (توجد علاقة وأثر ذات دلالة معنوية بين بين إدارة الخدمات الإلكنزونية ومعوقات تطبيقها). ب. فرضية البديل والذي نصه (لا توجد علاقة وأثر ذات دلالة معنوية بين بين إدارة الحخدمات الإلكتزونية ومعوقات تطبيقها). 


\section{الخور الأول: الحلدمات المصرفية مفهومها أنواعها أمميتها}

أولاً: مفهوم الحدمة المصرفية:

لقد اعطيت مفهوم الخدمة المصرفية تعاريف متعددة، والتي إن اختلفت فإنها تشتزك أحياناً في معنى أو أكثر، حيث نجـد

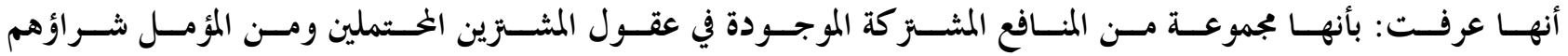

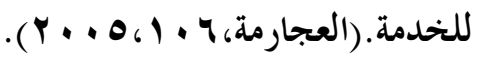

كما عرفت بأنها" كافة الأنشطة والعمليات التي يبرز فيها الجانب غير الملموس بشكل أوضح من الجانب الملموس والـتي يتولـد

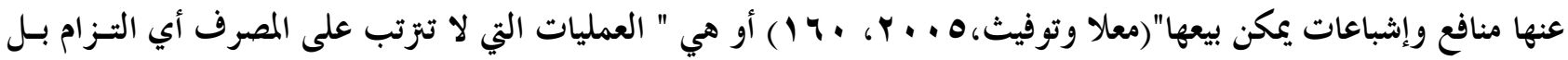
هي خدمات يقدمها المصرف إلى زبائنه لقاء أجر يتقاضاه أو ودائع يقبلها من المدخرين ويعيد توظيفها بفائدة تفـوق الفائسدة الـتي

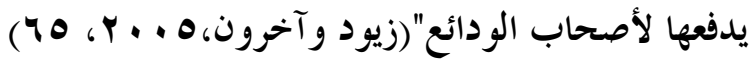
والذي يبينها التعريفات السابقة هي أن الخدمة المصرفية بجموعة من العمليات التي يقوم بها البنك بتقديمها لعملائه، وهـي نشـاط أو مجموعة من الأنشطة التي يكون جوهرها غير ملموسة والتي يكون الهدف منها تحقيق رضا الزبون، وقد ترتبط عمليسة إنتاجها لتها بمنتج مادي أو لا ترتبط، ولا توجد فيها انتقال للملكية. وبهذا فقد اشتمل مفهوم الحخدمة المصرفية بعدين اساسيين هما: البعد الفني والبعد الوظيفي: فالبعد الفني مجموعة من المنافع التي يسعى العميل إلى تحقيقها من استخدامه للخدمة المصـرفية، ففي

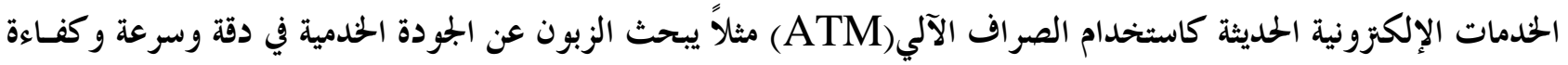
الصراف الآلي وانعدام الانعطال فيه، أما في البعد الوظيفي الذي يتمثل في مجموعة الحخصائص التي تنصف بهـا الحخدمـة المصـرفية، ففي حالة إيداع مبلغ من المال في المصرف يبحث الزبون عن تعامل وسلوك العاملين والموظفين في المصرف وطريقة تعاملـهم مـع

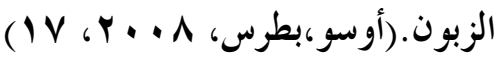

\section{ثانياً: أهمية المالدمة المصرفية:}

إن الحذمات المصرفية الإلكتزونية في المصارف بصفة عامة هي الواجهة الرئيسية للمتعاملين مـع المصـرف ووسـيلة هامـة لجـذب المتعاملين الجددد والخافظة علي المتعاملين الحاليين, فهي بوابة العبور للتعامل في أنثطة المصرف المختلفة، هذا فضلاً عـن إيراداتها وإنخفاض خطورتها للبنك. كما أن الحدمات التي تقدمها المصارف لزبنائها تمثل أحد الأنشطة الإقتصادية الهامة في أي دولة، وذلك لأنها كنشـاط اقتصـادي

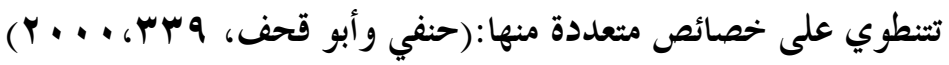
ا- الخدمات المصرفية تعمل في مجالات متعددة ومختلفة، بحيث مرتبطة بجميع الأنثـطة الإقتصـادية والإجتماعيـة الأخسرى للدولة. ץ- إن مستوى الطلب على الحخدمات المصرفية دالة في درجة التقدم الإقتصـادي للدولـة، إذ أن الحخدمـة المصـرفية نشـاط انتاجي ذا طبيعة خاصة ويرتبط بقضايا التنمية بمجالاتها المتعددة. 
بـ- إن الطلب على الكثير من الحذدمات المصرفية يتصف بصفة التكرار، هذا فضلاً عسن أن هـذه الحسدمات تعتسبر صسناعة

حيث يتوافر فيها كل متطلبات وعناصر أي نشاط إنتاجي آخر.

وأن توافر هذه الخصائص يعني ضرورة مواكبة النشاط المصرفي لمنطلبات النطور في جميع أوجه النشاط الإقنصادي والإجتماعي في أي دولة بغض النظر عن طبيعة نظامها الإقتصادي أو فلسفتها السياسية.

\section{ثالثاً: أنواع الحلدمات المصرفية تنقسم الحذدمات المصر فية إلى قسمين أساسيين:}

1: الملدمات المصرفية الثقليدية:

يقصد بالخدمات المصرفية التقليدية الحخدمات التي تقدمها المصارف لزبنائها داخل المصرف، أي لا يستطيع الزبون الاستيفادة مسن هذه الحذدة من بعيد بل يجب عليه الحضور للمصرف للاستفادة منها، وظهر مصطلح التقليدية بعد ظهور واستخدام التكنولوجيا بشكل واسع في الحدمات المصرفية، ونستطيع أن نلخص الحذدمات المصرفية التقليدية كالآتي: أ- فتح الحسابات المختلفة للعملاء (الحساب الجاري - حساب التوفير - الحساب لأجل). ب- تقديم القروض للعملاء، حيث تعد هذه الوظيفة الاستثمار الرئيس للبنوك التجارية. تـ- اصدار خطابات الضمان والاعتمادات المستندية لتسهيل العمليات الجحارية، خصوصاً الحارجية منها. ثـ- بيع وشراء الأوراق المالية وتحصيل الأوراق التجارية لصالح العملاء، وتقديم الحخدمات الاستشارية للزبائن المتعلقــة

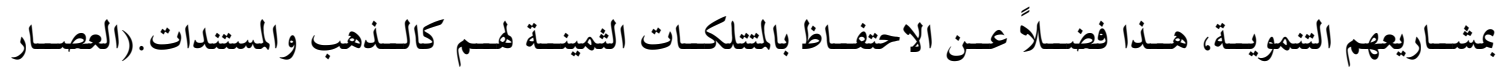

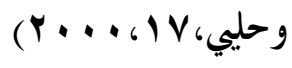

\section{ب- الحلدمات المصرفية الإلكرونية:}

قد مرت الحذمات المصرفية كغيرها من النشاطات الإقتصادية بالعديد من مراحل التطور، وأن تطسور الجُتمعـات وتغسير حاجـات العملاء لزمت البنوك على أن تواكب هذا التغير وتقدم خدمات تتماشى مع متطلبات الواقع، حيث أدت التطورات الحاصسلة في تكولوجيا الاتصالات والمعلومات التي شهدها العصر إلى ظهور تغيرات جوهرية في عمل المصارف، فقد تحول نشاط البنسوك مـن مجرد القيام بدور الوسيط بين المودعين والمقتزضين وما يرتبط بها من أنثطة مصرفية إلى تنوع وتعدد الخدمات والأنشطة الحديثـة معتمدة في ذلك على مختلف الأنظمة والاستزاتيجيات في البجال الإلكتزوني من أجل الحفاظ على مكانتسه المصـرفية واستقر اره في ظل التغيرات الحاصلة في كل الجالات، فضلاً عن وقوفه في وجه المنافسين. نستطيع أن نشيز إلى أهم الحخدمات الإلكتزونية كالآتي:

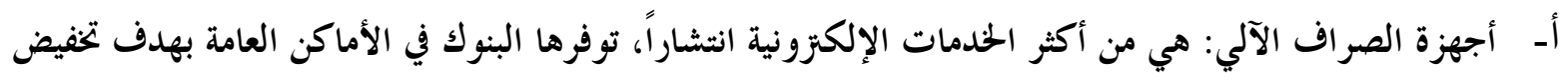
ضغط العمل وتجنب الاجراءات الإدارية وتلبية حاجات العملاء المالية بعد أوقات العمـل، وتعمـل خـلال العطـل وعلى مدار ع Y ساعة، وتعمل بواسطة بطاقة الكتزونية يحملها العميل يدخلها برقم سري، وهي وسيلة تستخدم في

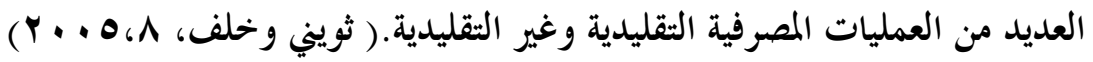


ب- خدمة البنك الماتفية: هذه الخدمة تمنح العملاء من دخول حساباتهم البنكية من خلال هواتفهم الخمولة والـتحكم بحساباتهم واجراء العمليات التي يريد أن يقوم بها العميل من الدفع وتحويل الأموال من دون الحضسور إلى البنـك،

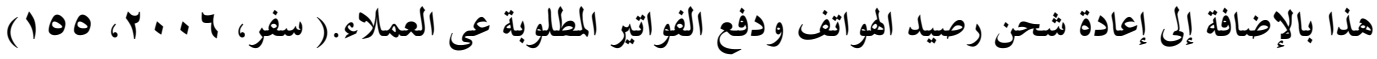
ج- الحخدمة المصرفية عبر الانتزنت: في هذه الحذدمة تكون الانزنت وسيلة للاتصال بـين البنـك والعميـل، وذلـك مـن خلال الدخول إلى الصفحة الإلكتزونية للبنك، حيث تسمح هذه الحخدمة للعملاء الذين لـديهم بطاقـات السـحب الآلي من الدخول لمعلوماتهم المصرفية من أي مكان وعلى مدار السـاعة للـتحكم بحسـاباتهم واجسراء العمليـات.

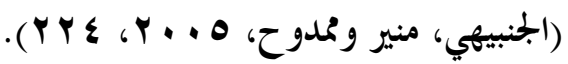

د- البطاقات البلاستيكية الممغنطة: وهي البطاقات المدفوعة مسبقا، تكون القيمة المالية مخزنـة فيها، ويمكـن اسـتخدام هذه البطاقات للدفع عبر الإنتزنت وغيرها من الشبكات، كما يمكن استخدامها للـدفع في نقـاط البيـع التقليديـة

(Point of Sales)

\section{الخور الثاني: إدارة الحدمات الإلكزونية المصرفية والتحديات التي تواجهها}

\section{أولاً: إدارة الحدمات المصرفية الإلكورنية}

تحتاج الحخدمات المصرفية الإلكتزونية إلى عدة متطلبات أساسية تجب تو افرها لإدارتها، ويهيئ البيئة المناسبة والمؤاتية لطبيعـة هـذه

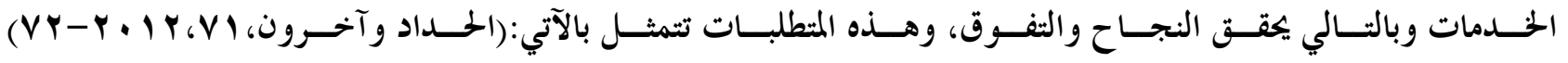

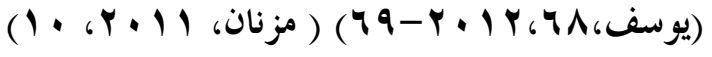

ا - البنية التحثية: الإدارة الإلكتزونية تتطلب وجود مستوى مناسب وعال من البنية التحتية التي تتضمن سير الحسدمات في ظلها بشكل سلس، والتي تتضمن شبكة حديثة للاتصالات والبيانات وبنية تحتية متطورة للاتصالات تكون قادرة على تأمين التواصل ونقل المعلومات بين المؤسسات الإدارية نفسها من جهة وبين المؤسسات والمواطن من جهة أخرى، فمهما

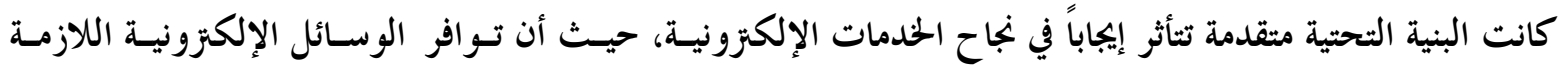
وغيرها من الأجهزة التي تمكننا من الاتصال بالشبكة العالمية أو الداخلية في البلد وبأسعار معقولة تتيح لمعظم المـواطنين

$$
\text { الحصول على هذه الحذدمات الإلكتزونية وتسهل إدارتها. }
$$

ץ- عنصر الأمان: وهي تتمثل باستخدام تقنيات وأساليب متعددة لتوفير عنصر الأمان من أجل حماية شبكة وأنظمة البنـك الداخلية من عمليات الهجوم الإلكتزوني، حيث أن توفير الأمن الإلكتزوني والسرية الإلكتزونيسة على مسـتوى عـال لحماية المعلومات العملاء ولصون الأرشيف الإلكتزوني من أي عبث والتزكيز على هذه النقطة لها من أهمية خاصسة في إدارة هذه الحخدمات.

ب- الكوادر البشرية الكفوءة: إن من مستلزمات تطبيق الحخدمات الإلكتزونية وجود وتوفر كوادر بشـرية مؤهلـة القـادرة على أداء الأنماط الجديدة من العمل القائم على التقنيات الحديثة، وهذا يتطلب تواصل التأهيل والتسدريب للكـوادر في 
مختلف الوظائف الفنية والمالية والتسويقية والاستشارية والإدارية، كما أنه يجب نشــر ثقافـة اسـتخدام هـذه الحـدمات وطرق ووسائل استخدامها للمو اطنين أيضاً.

ع - التقييم المستمر: من متطلبات استمرارية تطبيق الحخدمات المصرفية التقيسيم الموضسوعي والمسـتمر لفاعليـة أداء أدواتها الإلكتزونية، وذلك بالاستعانة بالجهات والكو ادر المتخصصة من اجل معرفة سلامة ادائهـا والوقـوف على الصسعوبات التي تواجه عملها، واتخاذ القرارات والإجراءات المناسبة للحد منها. ه- توافر خدمة الانتزت بين المواطين بشكل واسع وبأسعار معقولة قدر الإمكان، فإن ذلك يسهل فتح الجحال لأكبر عدد ممكن من المواطنين للتفاعل مع الإدارة الإلكتزونية في أقل جهد وأقصر وقت وأقل كلفة ممكنة. צ- وجود التشريعات و النصوص القانونية التي تسهل عمل الإدارة الإلكتزونية وتضفي عليها المشروعية و المصداقية وكافة النتائج القانونية المثزتبة عليها.

\section{ثانياً: التحديات التي تواجه الحثدمات المصرفية الإلكرونية}

بالرغم من وجود الأهمية المائلة للخدمات الإلكتزونية المصرفية إلا أن هناك بعض معوقات ومخاطر تواجه تطبيق العمـل

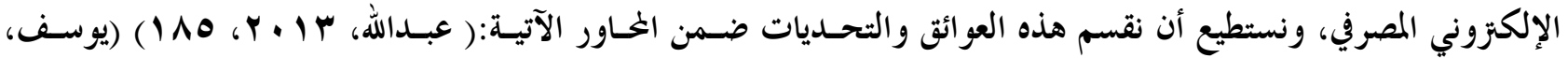

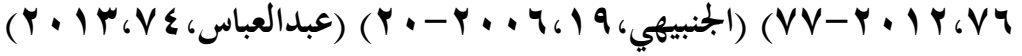
ا- التحديات الإدارية والتظيمية: إن من أهم التحديات الـتي تقـف في وجـه إدارة وتطبيـق الحــدمات الإلكتزونيسة المصرفية هي التحديات الإدارية والتنظيمية داخل البنك، حيث هناك في كثير من البنوك ضعف في إعـادة هندسـة العمل المصرفي وتكيفه مع الأسلوب الإلكتزوني الجحديد، هـذا ناهيـك عـن مقاومـة المـوظفيين المصـرفيين لاعتمـاد الأسلوب الإلكتزوني في تسويق الخدمة المصرفية بالجودة المناسبة ورغبتهم باعتماد الأسلوب التقليدي في التسـويق المصرفي. وهذا ينشئ أحياناً من خلال عدم وجود المعرفة الإلكتزونية الجيدة في التعامل مع الأجهزة والمعـدات، ممـا قد يسبب أحياناً إلى توقف النظام وأخطاء المعالجة وخلل في البرمجيات وأخطاء التشغيل وتعطل النظسام وضسعف في المر اقبة وقصور في الحماية ويعرض البنك للهجمات الإلكتزونية والاختزاقات وعملية الاحتيـال، وفي الأخسير عـدم القدرة الملائمة على التعافي. ץ- التحديات الأمنية: تنشأ هذه التحديات نتيجة الاختزاق الأمني للشبكة وامكانية سـرقة امـوال العمـلاء مـن قبـل الآخرين، أو إساءة الاستخدام من قبل العملاء، بالإضافة إلى وجـود احتيـالات الكتزونيـة وتزويـر العنـاوين الـتي تتطلب إفشاء معلومات تتعلق بأمن العملاء، الأمر الذي يضر بسمعة البنـك وينشيء الـرأي السـيبي للجمهـور، ويسبب بطريقة أو بأخرى من نفور العملاء. ب- التحديات الثقنية وضعف استخدامها: وهي متعلقة بصعوبة الحصول على الأجهزة الحاسـوبية المتقدمـة وضسعف شبكات الاتصال والتغطية الإلكتزونية من قبل العملاء، بالإضافة إلى صعوبة استخدام هذه التقنيات وضعف المعرفة الإلكتزونية من قبل الجماهير والعملاء والانتشار النسيي بينهم. بالإضافة إلى تردد العمـلاء مـن التعامـل مـع هـــا الأسلوب إلى جانب عدم ثقتهم به للحصول على الخدمات المصرفية المطلوبة. 
ع - التحديات القانونية والتشريعية: وهي التي ترتبط بضعف الأنظمة والقوانين والتشريعات التي تحد من التجاوز على

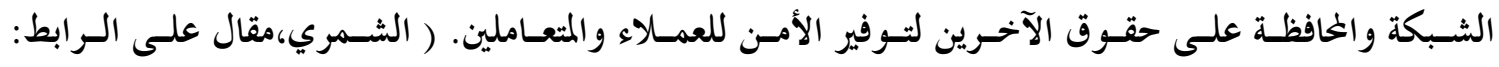
(http://fcdrs.com عادل شمران الشمري. هـ - التحديات الثمويلية: بما أن الحذدمات الإلكتزونية تعتمد على أجهزة متطورة وتقنيـات حديثـة إلى جانسب بــرامج ودورات تدريبية مستمرة لنطوير المنتسبين، فإن هذا يحتاج إلى تمويل وتخصيصات مالية جيدة ودائمة، الأمر الـذي بـابي كثير من البنوك لا يستطيع ادامته. ף- التحديات التنافسية: حيث وفر شبكات الانتزنت فرصة كبيرة للتنافس من خلال خلق خدمة واسعة من الخدمات التي أصبح بالإمكان تقديمها، وهذا الوضع يعرض البنوك الموجودة الخلية في عالمنا المتخلف إلى مخاطر حتمية، إذ تجد هذه البنوك الخلية نفسها في منافسة غير متكافئة مع البنوك العالمية التي تنوعها بشكل كبير.

\section{الغحور الثالث : الجانب الميداني للبحث}

\section{اولاً: وصف مجتمع البحث وعينته}

تناول الإطار الميداني للبحث مجموعة من البنوك التي كانت تضطلع بتقديم خدمة أو بعض الحخدمات المصـرفية الإلكتزونيـة منهـ (بنك الثمال، بنك دجلة والفرات، بنك هولير، بنك موصل) حيث تم اختيارها كمجتمع للبحث ضمن الحدود الجغغرافية لخافطة السليمانية. وقد تم توزيع استمارة الاستبيان على المدراء ورؤساء الأقسام وموظفين في البنسوك المبحوثـة، وتم اسـتخدام اسـلوب العينة العشو ائية عند توزيع الاستبانة، حيث تم توزيع (0 ( ) استمارة و كانست عـدد الاسـتمارات المسـتزدة والصـالحة للتحليـل الإحصائي(ه) استمارة ويمكن ملاحظة الرموز والعبارات الواردة في الاستبيان كما هـي في (الملحسق رقـم ( )، وقـد تم تفريـغ البيانات ومعالجتها باستخدام البرجية الإحصائية للعلوم الاجتماعية

ثانياً: اختبار الثبات: لغرض التأكد من ثبات المقياس المستخدم تم استخدام معامل (Cronbach Alpha) للوقوف على دقة إجابات افراد مجتمـع

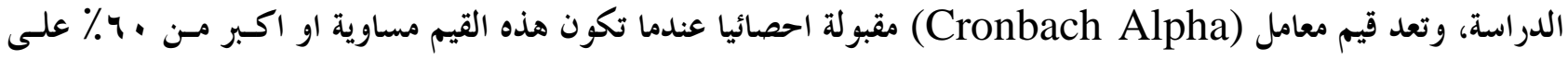
وجه التحديد في البحوث الادارية. وان قيمة (Cronbach Alpha) تساوي (YAV , • ) على مستوى الاجمالي للمتغيرات.

\section{ثالثاً: وصف بيانات الشخصية لعينة الافراد المستجيبة في البنوك المبحوثة:} لمعالجة مشكلة الدراسة وانسجاما مع أهدافها فقد تم تصميم استمارة الاستبيان لتوضيح و طـرح عـدد مـن الفقـرات، وكانست

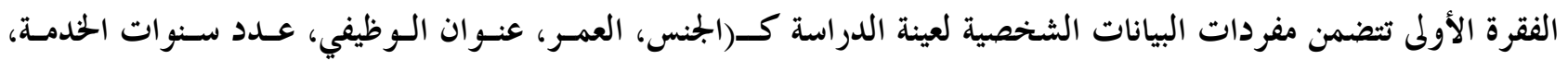
الشهادات) و كانت التكرارات والنسب المئوية لبيانات الشخصية في البنوك المبحوثة كما هو مبين في الجمدول رقم ( ) ادناه. 


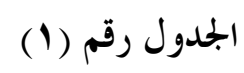

التكرارات والنسب المئوية للمتغيرات الشخصية لعينة الدراسة في المصارف المبحوثة

\begin{tabular}{|c|c|c|c|}
\hline$\%$ & 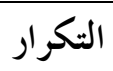 & \multicolumn{2}{|c|}{ العبارات (المتغيرات الوصفية بعينة الدراسة) } \\
\hline$\varepsilon \cdot, V$ & $r \varepsilon$ & 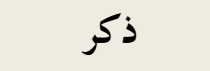 & 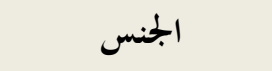 \\
\hline$\bullet q, r$ & ro & انثى & \\
\hline 17,9 & 1. & $r q-11$ & العمر \\
\hline rq & rr & $r q-r q$ & \\
\hline$M, r$ & 19 & $\varepsilon q-p q$ & \\
\hline 11,9 & V & 9 \ فاكثر & \\
\hline $7, \wedge$ & $\varepsilon$ & مدير & عنو ان الوظيفي \\
\hline rw,q & $r \cdot$ & مسؤول شعبة & \\
\hline ru,q & $r \cdot$ & مسؤول وحدة & \\
\hline$r \bullet, \varepsilon$ & 10 & موظف & \\
\hline $10, \mu$ & 9 & اقل من • & عدد سنوات الحخدمة \\
\hline ru,q & $r \cdot$ & $1 \cdot-7$ & \\
\hline ro, & Y & $10-11$ & \\
\hline $10, \mu$ & 9 & ه 1 فأكثر & \\
\hline $1, \mathrm{~V}$ & 1 & دون الثانوية & الشهادات \\
\hline$r \cdot, r$ & Ir & ثانوية & \\
\hline rq & rr & 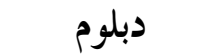 & \\
\hline pq & $r r$ & بكالوريوس & \\
\hline
\end{tabular}

الجددول من اعداد الباحثين

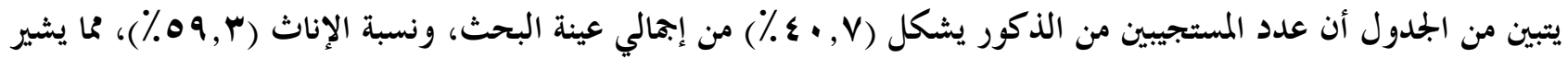
إلى ان نسبة الاناث تفوق الذكور بنسبة(9 1\%) في عينة البحث في المصارف المبحوثة.

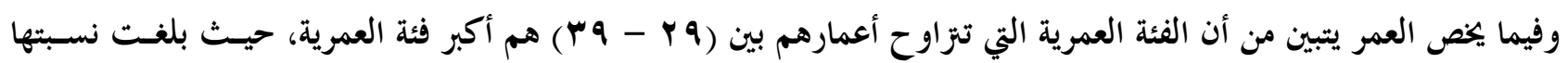

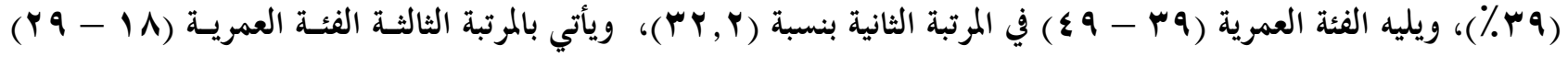

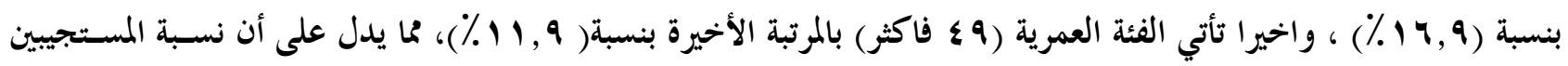
من العاملين للعينة تقع أعمارهم ضمن الفئة العمرية الناضجة والشابة والمتوسطة في المصارف المبحوثة والذي يسهل الإجابة على الاستبيان بشكل واضح. 
والعنوان الوظيفي لعينة البحث تشير إلى أن نسبة مسؤولي الشعب والوحدات كانت تشكل أعلى النسب مسن بـين المستجيبين

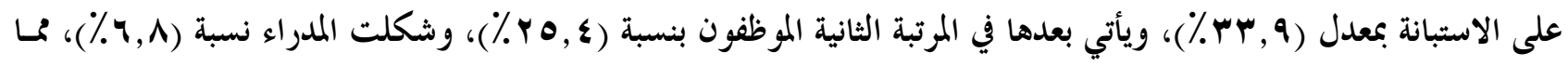

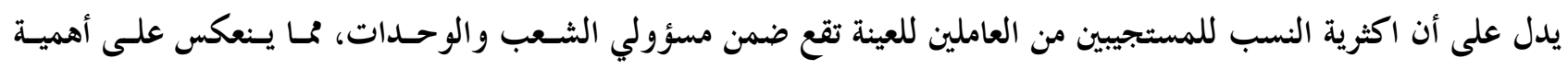
الاستجابات وواقعيتها، والذي يساعد الإجابة على الاستبيان بشكل دقيق ومفهوم.

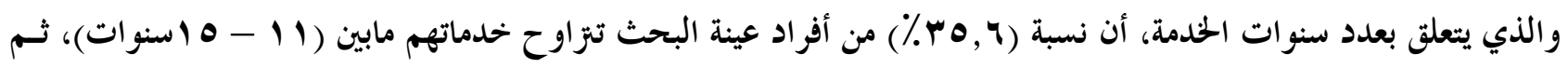

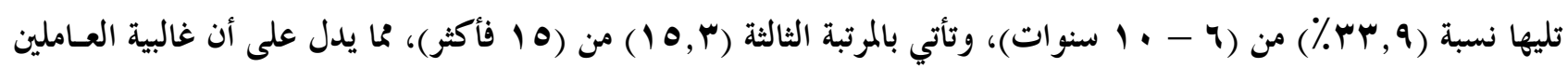
الحاليين لاتقل خبراتهم عن ها سنوات، ويساعد هذا على الإجابة على الاستبيان بشكل واضح، ومما تعكس هذه النسبة أهميـة البيانات التي وافتنا بها هذه الفئة والذين لديهم خبرة في العمل المصرفي.

والمؤهل العلمي لعينة الدراسة تشير إلى أن نسبة الحاصلين على شهادة البكالوريوس والدبلوم كانت تشكل أعلى النسب من بين

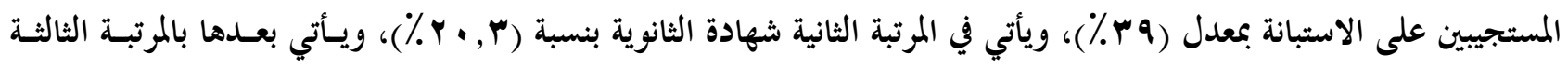

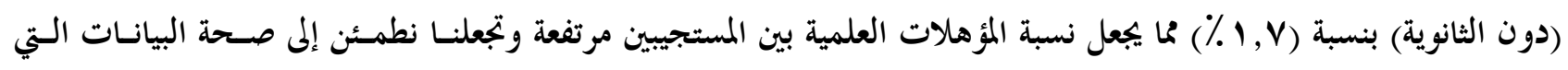
حصلنا عليها، وان اجوبتهم لاستمارات الاستبيان لن يكون عشو ائية بل بطريقة علمية وفهم عميق لغتنوياتها.

رابعا: عرض وتحليل إجابات المبحوثين لعينة الدراسة:

لقد تم استخدام مقياس ليكرت الخماسي (1 - ه ه ) والبرمجة (SpsS 16.0) لمعرفة مدى الاتفاق أو الاختلاف بين أفـراد عينسة

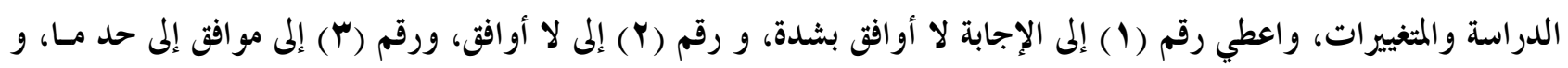

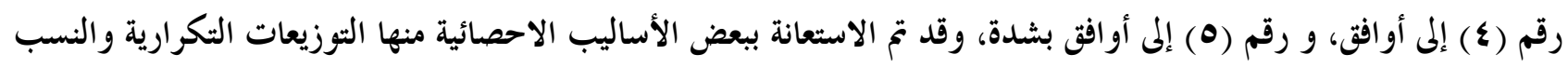
المئوية والوسط الخسابي والانحراف المعياري، والانحدار الخطي والارتباط كما يأتي:

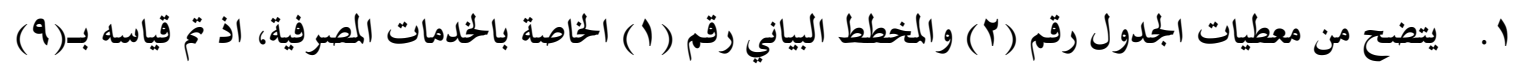

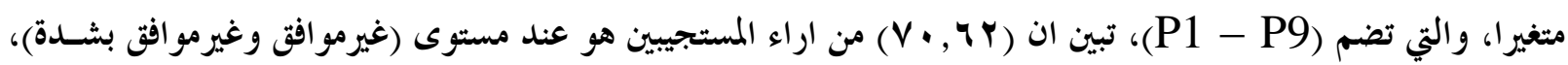

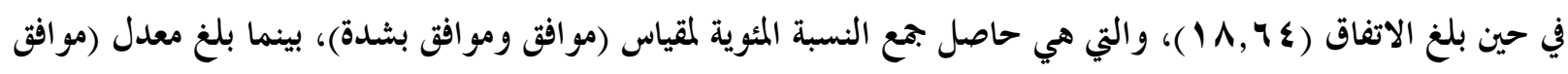

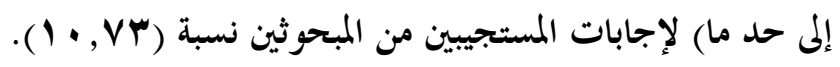

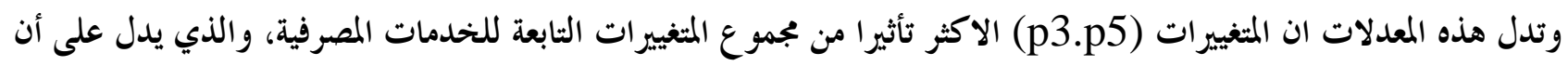
توفير الحذدمات الإلكتزونية يساهم في تخفيض ضغط العمل وتقليل الاجراءات الادارية وتلبية حاجات العملاء المالية بعسد اوقـات العمل، ويساهم الحذدمات الإلكتزونية بتوفير وتقديم الحخدمات من خلال الهو اتف الخمولة والتحكم بحساباتهم واجـراء العمليـات

$$
\text { بسهولة ويسر . }
$$

وأما ما يتعلق بقياس وتحليل الوسط الحسابي والاخراف المعياري بين متغيرات الدراسة، ظهرت أن الوسط الحسابي لإجابات

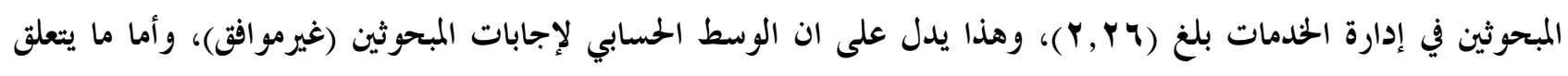
بالانحر اف المعياري يظهر أن إجابات المبحوثين لعينة الدراسة لإدارة الحدمات يبلغ (ع إ • )، وهذا يدل على تقارب وتجانس اراء المستجيبين لعينة البحث لمتغير إدارة الحذدمات المصرفية. 
الجددول رقم (؟) الثوزيعات التكرارية والنسب المئوية لمتغيرات الحخدمات المصرفية

\begin{tabular}{|c|c|c|c|c|c|c|c|c|c|c|c|c|}
\hline \multirow{3}{*}{ الالمعياري } & \multirow{3}{*}{ المتوسط } & \multicolumn{10}{|c|}{ مقياس الإجابة } & \multirow{3}{*}{ المتغييرات } \\
\hline & & \multicolumn{2}{|c|}{ لا اوافق بشدة } & \multicolumn{2}{|c|}{ لااوافق } & \multicolumn{2}{|c|}{ مو افق إلى حدما } & \multicolumn{2}{|c|}{ مو افق } & \multicolumn{2}{|c|}{ مو افق بشدة } & \\
\hline & & $\%$ & التكرار & $\%$ & التكرار & $\%$ & التكرار & $\%$ & التكرار & $\%$ & التكرار & \\
\hline$\cdot, \leqslant \wedge$ & $1, r \varepsilon$ & 74,1 & $r q$ & $r r, q$ & $r$. & . & . & . & . & . & . & $\mathrm{p} 1$ \\
\hline$\cdot, \cdots$ & $r$ & . & . & $1 \ldots$ & 09 & . & . & & & . & . & $\mathrm{p} 2$ \\
\hline $1, \varepsilon r$ & $r, 9 \wedge$ & qu, & $r$. & & & - & . & 74,1 & $r$. & & & p3 \\
\hline$\cdot, \leqslant \wedge$ & 1,79 & qu, q & $r$. & 97,1 & $r q$ & . & . & & & & & $\mathrm{p} 4$ \\
\hline$\cdot, \leqslant V$ & $r, \uparrow \wedge$ & . & . & & & $r r, r$ & 19 & $T V, \Lambda$ & $\varepsilon$. & . & . & $\mathrm{p} 5$ \\
\hline • & $r$ & . & . & rr,q & $r$. & $r r, r$ & 19 & rr,q & $r$. & . & . & p6 \\
\hline$\cdot, \leqslant V$ & 1,71 & Tr,Y & 19 & $7 V, \Lambda$ & $\varepsilon$. & . & . & & & & & P7 \\
\hline$\cdot, \leqslant V$ & 1,71 & Tr, Y & 19 & $7 V, \Lambda$ & $\varepsilon$. & . & . & & & & & P8 \\
\hline$\cdot, \leqslant V$ & $r, M r$ & . & . & $7 V, \Lambda$ & $\varepsilon$. & rr, r & 19 & & & . & . & P9 \\
\hline$\cdot, 1 \varepsilon$ & $r, Y Y$ & \multicolumn{2}{|c|}{ rrT } & \multicolumn{2}{|c|}{$\varepsilon \wedge, \diamond \wedge \wedge \wedge q$} & \multicolumn{2}{|c|}{ rrru, 1. 1 } & \multicolumn{2}{|c|}{$1 \wedge, 7 \leq \varepsilon \leq$} & \multicolumn{2}{|c|}{ - } & المعدل \\
\hline
\end{tabular}

المصدر: من اعداد الباحثان على ضوء نتائج البرنامج الاحصائي SpsS.

الشكل رقم ( ا ) النسب المئوية لمتغيرات الحخدمات المصرفية

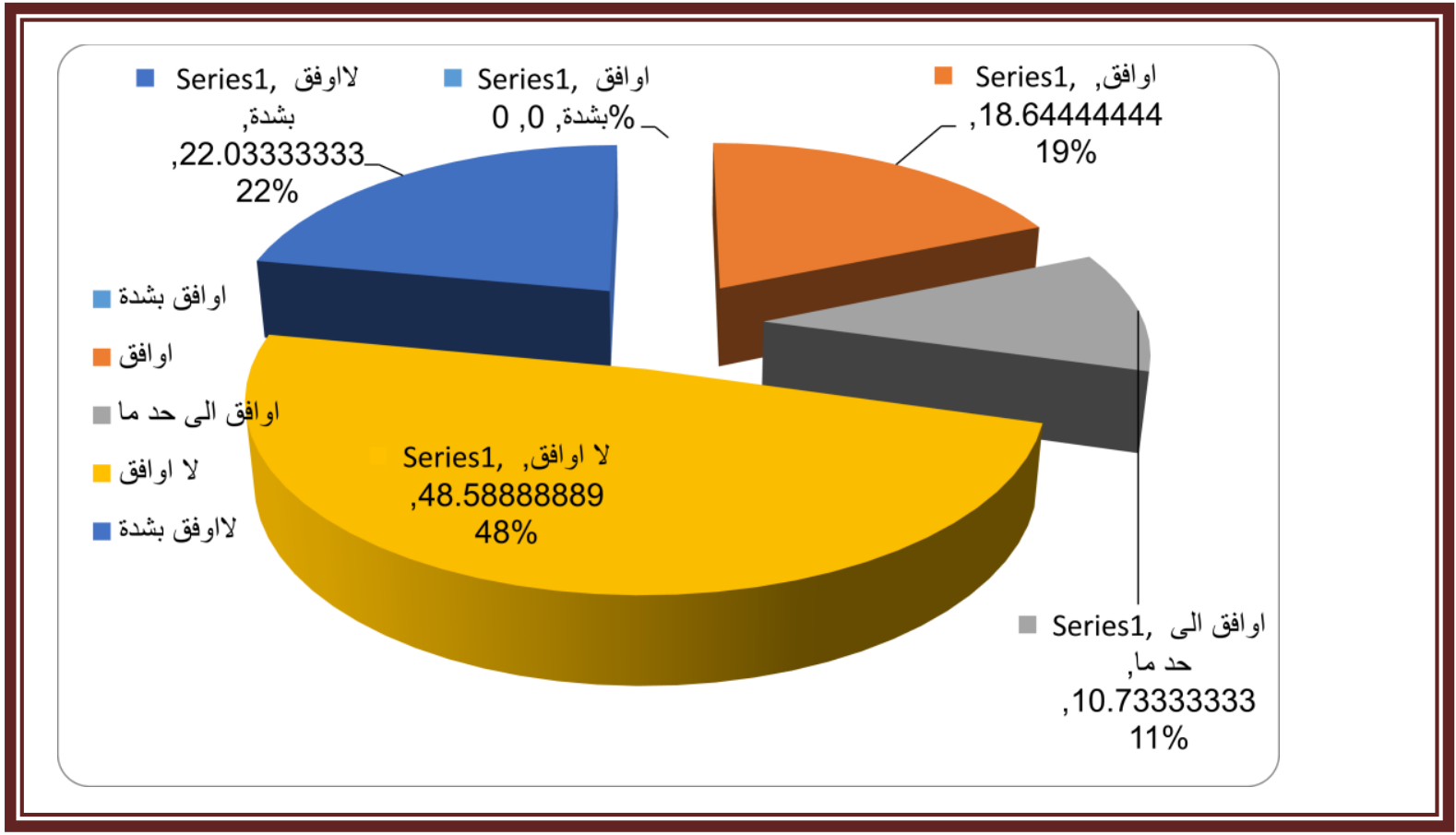

المصدر: من اعداد الباحثان على ضوء نتائج البرنامج الاحصائي SpSS. 
Y. يتضح من معطيات الجدول رقم (Y) والمخطط البياني رقم (Y) الخاصة بمعوقـات تطبيـق الإدارة الإلكتزونيسة، اذ تم قياسـه

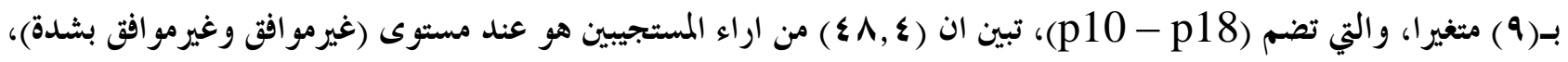

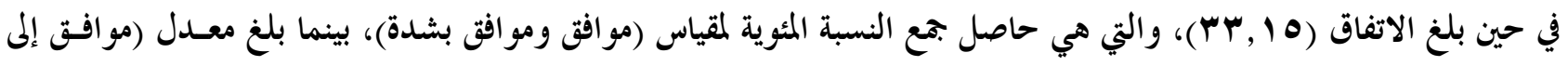

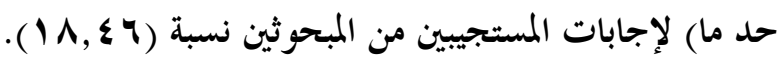
وتدل هذه المعدلات ان المتغييرات (p10,p12,p13) الاكثـر تـأثيرا مسن مجمسوع المتغسييرات التابعـة لمعوقـات تطبيـق الإدارة الإلكتزونية، والذي يؤشر على أن هناك ضعف في التكييف مع الأسلوب الإلكتزوني الجديد، ويرجع السبب إلى قناعـة العمـلاء

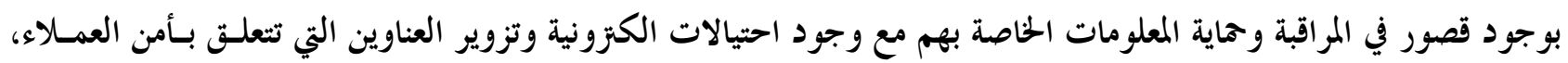
هذا من ناحية ومن ناحية أخرى صعوبة حصول المصرف على الاجهزة الحاسوبية المتقدمة وضسعف شـبكات الاتصـال والتغطيسة الإلكتزونية، وذلك لعدم دعم تلك المصارف من جانبين المادي والفني. وأما ما يتعلق بقياس وتحليل الوسط الحسابي والانحراف المعياري بين متغيرات الدراسة، ظهرت أن الوسط الحسابي لإجابات

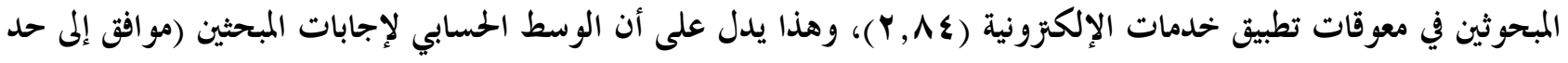
ما) لمتغير المعوقات، اما بالنسبة للانحراف المعياري يظهر أن جابات المبحوثين لعينة الدراسة لمعوقات تطبيق خدمات الإلكتزونية (9 ץ , •)، وهذا يدل على تقارب وتجانس المستجيبين لعينة البحث (اجوبة المبحوثين) لمتغيرات التابعة للمعوقات. الجدول رقم (ب) التوزيعات التكرارية والنسب المئوية لمتغيرات معوقات تطبيق الإدارة الإلكتزونية

\begin{tabular}{|c|c|c|c|c|c|c|c|c|c|c|c|c|}
\hline \multirow{3}{*}{ الانغر اف } & \multirow{3}{*}{ الوسطا } & \multicolumn{10}{|c|}{ مقياس الإجابة } & \multirow{3}{*}{ المتغييرات } \\
\hline & & \multicolumn{2}{|c|}{ لا اوانق بشدة } & \multicolumn{2}{|c|}{ لا اوانق } & \multicolumn{2}{|c|}{ موافق إلى حد ما } & \multicolumn{2}{|c|}{ موافق } & \multicolumn{2}{|c|}{ موافق بشدة } & \\
\hline & & $\%$ & التكرار & $\%$ & التكرار & $\%$ & التكرار & $\%$ & التكرار & $\%$ & التكرار & \\
\hline$\cdot, 90$ & r, r & - & - & qu, q & $r$ & & & 74,1 & pq & - & - & P10 \\
\hline $1, \varepsilon 1$ & $Y, 9 V$ & $7 \mathrm{~V}, \mathrm{\Lambda}$ & $\varepsilon$. & . & - & . & - & & & $r r, r$ & 19 & P11 \\
\hline$\bullet, \cdots$ & $\varepsilon$ & - & - & & & - & - & $1 \cdots$ & 09 & - & - & P12 \\
\hline $1,\{1$ & $r, \mu$ & $r, r$ & 19 & & & - & . & $7 \mathrm{~V}, \mathrm{\Lambda}$ & $\varepsilon$. & & & P13 \\
\hline$\cdot, \varepsilon \wedge$ & $Y, 7 Y$ & - & - & q, q & $r$ & 77,1 & pq & & & - & - & P14 \\
\hline$\cdot, \varepsilon \wedge$ & Y, Y & - & - & rr,q & $r$. & 77,1 & rq & & & - & - & P15 \\
\hline$\cdot, \varepsilon \wedge$ & $r, \mu \varepsilon$ & - & - & 77,1 & rq & q & $r \cdot$ & & & - & - & P16 \\
\hline$\cdot, \cdots$ & $r$ & - & - & $1 \cdots$ & 09 & - & - & & & - & - & P17 \\
\hline$\cdot, 9 \leq$ & $Y,\rceil \varepsilon$ & - & - & $7 V, \Lambda$ & $\varepsilon$. & & & r & 19 & - & - & P18 \\
\hline - rq & $Y, \wedge \varepsilon$ & \multicolumn{2}{|c|}{11.11111} & \multicolumn{2}{|c|}{37.28889} & \multicolumn{2}{|c|}{18.45556} & \multicolumn{2}{|c|}{29.57778} & \multicolumn{2}{|c|}{3.577778} & المعدل \\
\hline
\end{tabular}

المصدر: من اعداد الباحثان على ضوء نتائج البرنامج الاحصائي SpsS.

الشكل (ץ) التوزيعات التكرارية والنسب المئوية لمتغيرات معوقات تطبيق إدارة الحخدمات الإلكترونية 


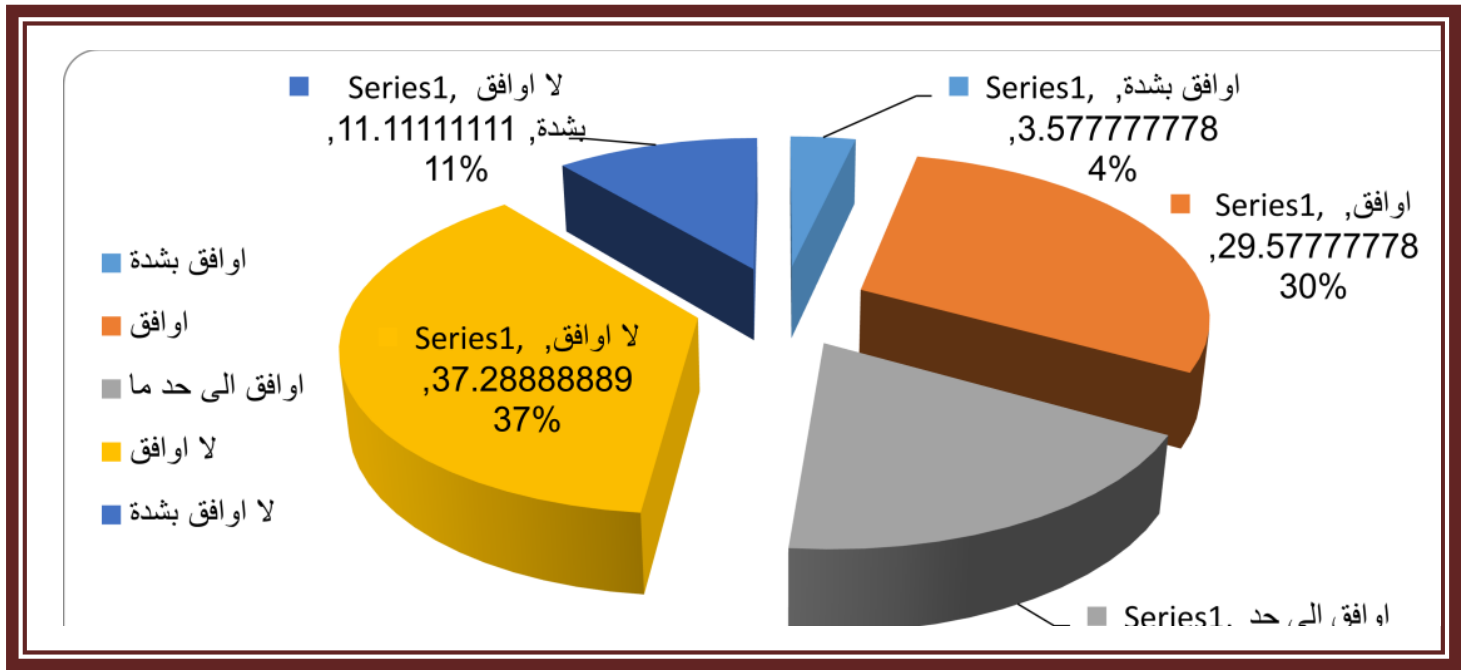

المصدر: من اعداد الباحثان على ضوء نتائج البرنامج الاحصائي SpsS.

اختبار الفرضيات:

I. اختبار الفرض الرئيس الاول كما يأتي:

ت. اختبار الفرض والذي نصه (توجد علاقة ذات دلالة احصائية بين إدارة الخدمات الإلكتزونية ومعوقات تطبيقها). ث. اختبار فرضية البديل والذي نصه (لا توجد علاقة ذات دلالة احصائية بين إدارة الحذدمات الإلكنزونية ومعوقات

تطبيقها).

$$
\text { ا ـ. اختبار الفرض الرئيس الثاني كما يأتي: }
$$

ت. اختبار الفرض والذي نصه (توجد علاقة وأثر ذات دلالة معنوية بين بين إدارة الحخدمات الإلكتزونية ومعوقات

$$
\text { تطبيقها). }
$$

ث. اختبار فرضية البديل والذي نصه (لا توجد علاقة وأثر ذات دلالة معنوية بين بين إدارة الخدمات الإلكتزونية

$$
\text { ومعوقات تطبيقها). }
$$

قام الباحثان باختبار الفرضيتين من خحلال اختبار متغيرات إدارة الخدمات الإلكتزونية ومعوقات تطبيقها، حيث استخدم الباحثون معامل ارتباط (Pearson) للاختبار على النحو التالي:

1 . يتضح من معطيات الجدول رقم (0) الخاصة بمعامل الارتباط ومستوى المعنوية Sig، ان إجابات المبحثين من عينة

الدراسة حول وجود علاقة ارتباط ومستوى المعنوية بين المتغييرين الرئيسيين إدارة الحخدمات الإلكتزونية ومعوقات تطبيقها، حيث يوجد علاقة متوسطة وطردية وموجبة بين إدارة الخدمات الإلكتزونية ومعوقات تطبيقها، وكانت نسبة

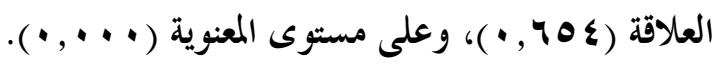

وبهذا يثبت الفرضية الرئيسية الاولى حول وجود علاقة ذات دلالة احصائية حيث بلغ نسبة العلاقة (ع ؟ , •)، ورفض فرضية البديل والذي نصه (لا توجد علاقة ذات دلالة احصائية بين إدارة الحذمات الإلكتزونية ومعوقات تطبيقها). 
وهذه النتيجة الرقمية (ع ه , • ) التي ظهرت من خلال التحليل تعني بأن هناك علاقة طردية وإيجابية بين إدارة الحذدمات الإلكتزونية ومعوقات تطبيقها في البنوك المبحوثة ومعناه بان على البنوك العاملة أن تتبنى وسيلة جيدة وفاعلة لتقديم الحدمات الإلكتزونية والعمل على اجتياز تلك المعوقات حيث يساعد ذلك على نجاح المصارف، حيث كلما عمل المصرف على اجتياز تلك المعوقات كلما أمكن على تقديم خدمات الكتزونية بصورة جيدة. الجمدول (0) الارتباط ومستوى المعنوية

\begin{tabular}{|c|c|c|c|}
\hline المعوقات & إدارة الخدمات & & \\
\hline$\cdot, 70\}$ & 1 & $\begin{array}{l}\text { Pearson } \\
\text { Correlation }\end{array}$ & \multirow{3}{*}{ إدارة الحدمات } \\
\hline$\cdot, \cdots$ & & Sig, (2-tailed) & \\
\hline 09 & 09 & $\mathrm{~N}$ & \\
\hline \multirow[t]{2}{*}{1} & $\cdot, 70 \varepsilon$ & $\begin{array}{l}\text { Pearson } \\
\text { Correlation }\end{array}$ & \multirow{3}{*}{ المعوقات } \\
\hline & $\cdot, \cdots$ & Sig, (2-tailed) & \\
\hline 09 & 09 & $\mathrm{~N}$ & \\
\hline
\end{tabular}

المصدر: من اعداد الباحثان على ضوء نتائج البرنامج الاحصائي SpsS.

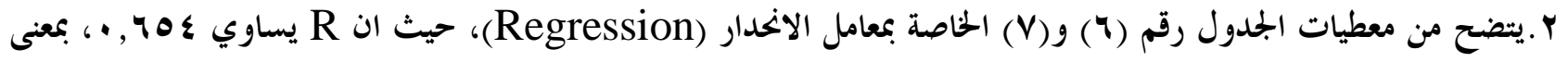
وجود علاقة طردية وموجية ومتوسطة وان التأثير يكون بشكل طردي، أي إذا كان التغيير ايجابي فإنه يؤثر على العامل التابع وإذا كان التغير سليي فإن التأثير على العامل التابع يكون سليي، وR square يساوي VY ع ع , •، بععنى أن أي تغير في العامل

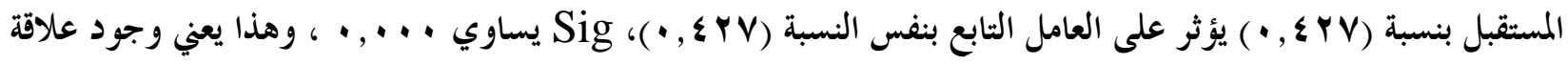
معنوية ذات دلالة احصائية، وهذا يثبت الفرضية الئيسية الثانية والذي نصه (توجد علاقة وأثر ذات دلالة معنوية بين إدارة الخدمات الإلكتزونية ومعوقات تطبيقها) ورفض فرضية البديل والذي نصه (لا توجد علاقة وأثر ذات دلالة معنوية بين بين إدارة الحذدمات الإلكترونية ومعوقات تطبيقها) حيث هناك علاقة وأثر على مستوى المعنوية ( ( . , •)، حيث يؤثر العامل المستقل (المعوقات) على العامل التابع (إدارة الخدمات) بصورة جيدة.

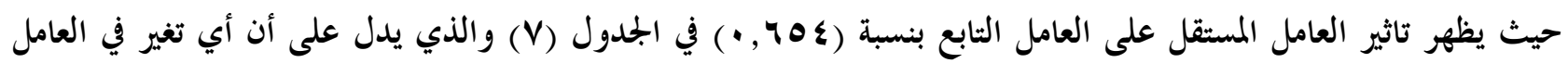
المستقل يؤثر بنسبة (0 7, • • ) على العامل التابع ·

الجمدول رقم (7) (7) (1)

MODEL SUMMARY

\begin{tabular}{|c|c|c|c|c|}
\hline Model & $\mathrm{R}$ & $\mathrm{R}$ square & $\begin{array}{c}\text { Adjusted R } \\
\text { square }\end{array}$ & $\begin{array}{c}\text { Std. error of the } \\
\text { estimate }\end{array}$ \\
\hline 1 & 0.654 & 0.427 & 0.417 & 0.10753 \\
\hline
\end{tabular}

المصدر: من اعداد الباحثان على ضوء نتائج البرنامج الاحصائي SpsS. 
(V) الجدول رقم

COEFFICIENTS

\begin{tabular}{|c|c|c|c|c|c|}
\hline \multirow[t]{2}{*}{ Model } & \multicolumn{2}{|c|}{ Unstandardized Coefficients } & $\begin{array}{l}\text { Standardized } \\
\text { Coefficients }\end{array}$ & \multirow[t]{2}{*}{$\mathrm{T}$} & \multirow[t]{2}{*}{ Sig } \\
\hline & $\mathrm{B}$ & Std. Error & Beta & & \\
\hline $\begin{array}{c}1 \\
\text { (CONSTANT) } \\
\text { Muaweq }\end{array}$ & $\begin{array}{l}1.370 \\
\text { • }\end{array}$ & $\begin{array}{l}0.137 \\
\cdot, \cdot \text { ^ A }\end{array}$ & $\cdot, 70 \leqslant$ & $\begin{array}{l}\text { 9, १AV } \\
\text { १,OYY }\end{array}$ & $\begin{array}{l}\cdot, \cdots \\
\cdot, \cdots\end{array}$ \\
\hline
\end{tabular}

المصدر: من اعداد الباحثان على ضوء نتائج البرنامج الاحصائي Spss.

\section{الغور الرابع: الإستنتاجات والتوصيات}

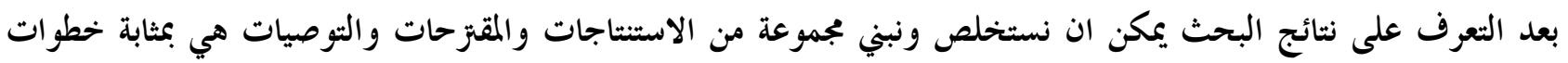

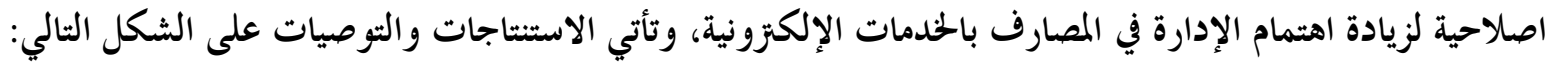

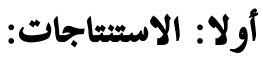

1 ا ـ إن إدارة الحدمات الإلكترونية ف إقليم كوردستان العراق تعاني من معوقات عدة، وعلى رأسها التكييف مع الأسلوب الإلكزوني الجديد، وخوف العملاء من التعامل بها الأسلوب، وصعوبة حصول المصرف على الاجهزة الحاسوبية المتقدمة وضعف شبكات الاتصال والتغطية الإلكنزونية. r. المصارف العاملة تعاني من ضعف في هندسة العمل المصرفي وتكيفه مع الأسلوب الإلكتزوني الجديد. r. ان استخدام التكنولوجيا في تقديم الخدمات الإلكتزونية والاستفادة منها بصورة جيدة، محدودة و ضئيلة، ولا تزال في بدايتها.

ع. تردد واضح من قبل العملاء في التعامل مع التقنيات الحديثة وذلك لعدم ثقتهم بها. ه. وجود تحدي من ناحية استخدام الاتمتة لحلق خدمة واسعة لانخفاض التخصصات المالية للتحول دون استخدام الحخدمات الإلكزونية، هذا من جانب ومن جانب اخر ندرة الكوادر الفنية في بلدنا. ه. أن العمل على تقديم الخدمات الإلكتزونية يوفر الجهد والوقت والكلفة للمصارف. 
إزاء النتائج العملية التي توصل الباحثان إليها فهما يوصيان المصارف العاملة في الإقليم بالمقتزحات الآتية من أجل التوسيع على استخدام الحدمات الإلكنزونية وبجودة جيدة: ا. . العمل على إزالة المعوقات المذكورة بهدف تقديم خدمات مصرفية الكتزونية عالية الجودة، لأجل البقاء على العملاء الحاليين وجذب عملاء آخرين. Y. تدريب و تنمية العاملين من ناحية الإدارية والتنظيمية بهدف إعادة هندسة العمل المصرفي. ب. ت تنويع وتوسيع الحدمات المصرفية الإلكتزونية والذي ينعكس دوراً إيجابياً في تحسين الحخدمات المصرفية كماً ونوعاً. ع. . العمل على إنشاء الثقة بين العملاء والمصرف من خلال توفير تقنيات حديثة متطورة وأكثر أمانا والعمل على دعم الأنظمة والقوانين التي تساهم في الخافظة على حقوق الآخرين. ه. توفير إمكانات مالية جيدة لغرض خلق وتوفير خدمات الكتزونية جيدة ومتنوعة. 4. . العمل على جذب المهارات والقدرات البشرية الكفوءة من ناحية استخدامها للتكنولوجيا الحديثة والمتطورة. V. العمل على توفير بنية تحيتة تكنولوجية متطورة لغرض نقل المعلومات بين المؤسسات المالية وتوفير الحخدمات الإلكتزونية للعملاء. 


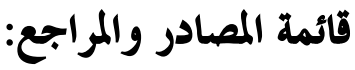

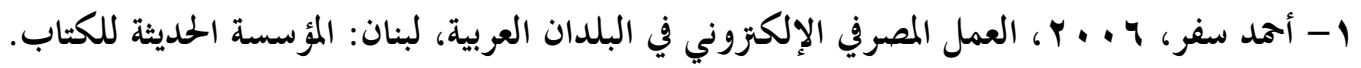

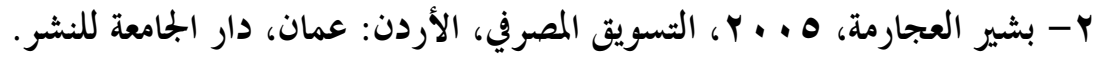

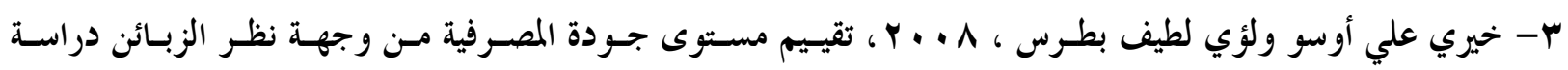

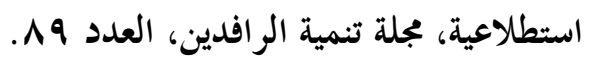

ع- رشاد العصار ورياض الحليي ، .... ب، النقود والبنوك، الأردن: عمان، دار صفاء للنشر.

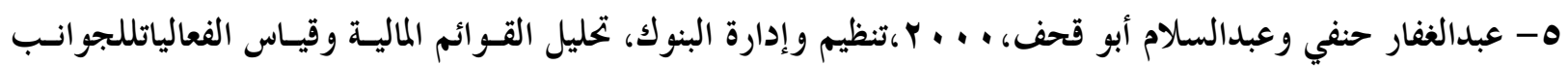
التنظيمية والإدارية، الأسكندرية: المكتب العربي.

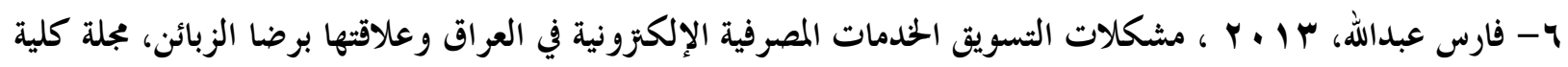
بغداد للعلوم الاقتصادية الجامعة، العدد الخاص.

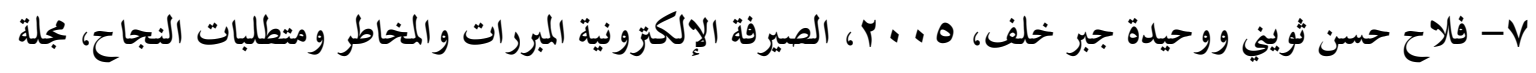

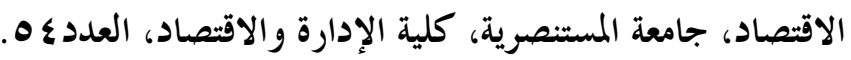

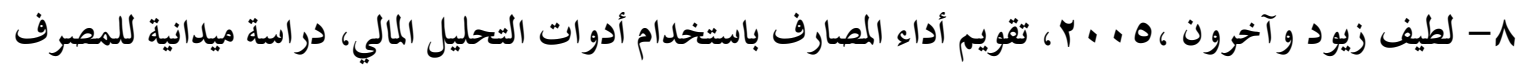

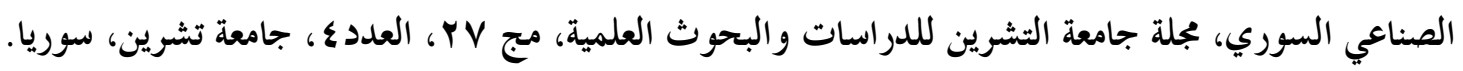

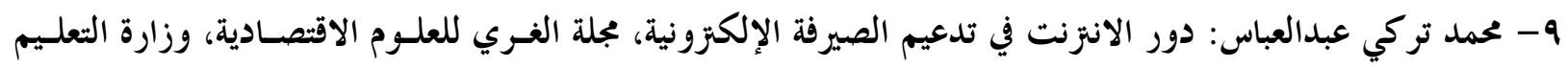

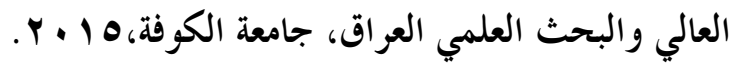

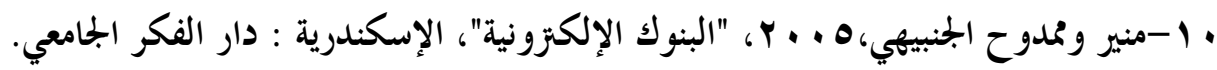

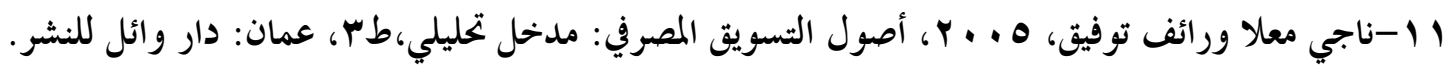

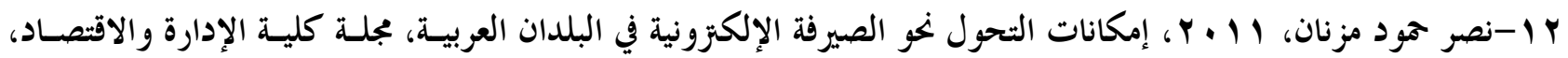

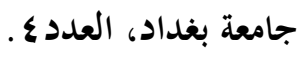

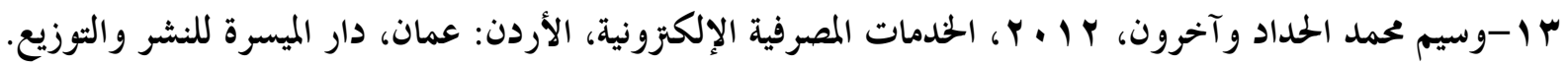

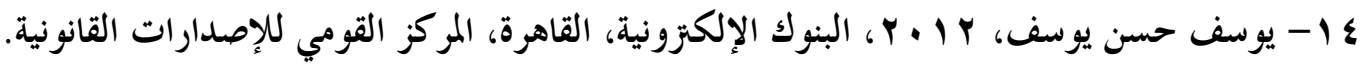




\section{الملحق رقم (1) استمارة الاستبيان}

$$
\text { م/استمارة الاستبيان }
$$

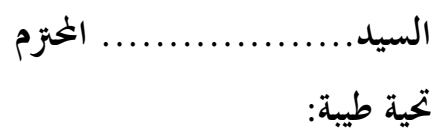

الاستبانة التي بين يديك تمثل جزء من مشروع بحث علمي في قسم العلوم المالية والمصرفية والموسوم (واقع إدارة المحدمات

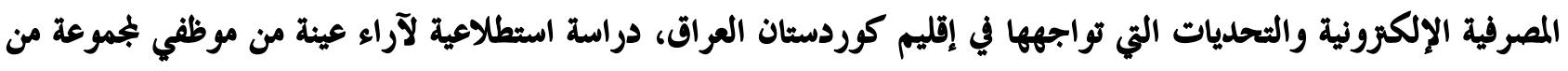

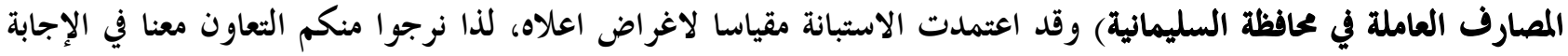

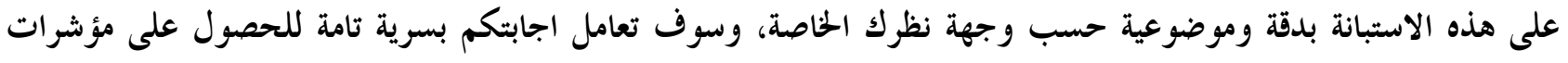
رقمية ولا تستخدم إلا لأغراض البحث العلمي. شاكرين حسن تعاونكم

الباحثان

م. كاوه محمد روستم

$$
\text { م.م. إبراهيم مهدي عارف }
$$




\section{ملاحظة: قبل الإجابة على فقرات الاستبانة يرجى ملاحظة ما يأتي:}

I. . ضع علامة ( П) ازاء الاختيار لكل سؤال يعكس وجهة نظرك فعليا.

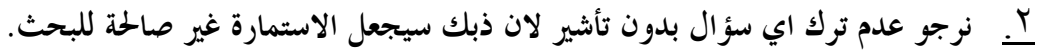

أولا: المعلومات او البيانات الحخاصة بالافراد عينة البحث:

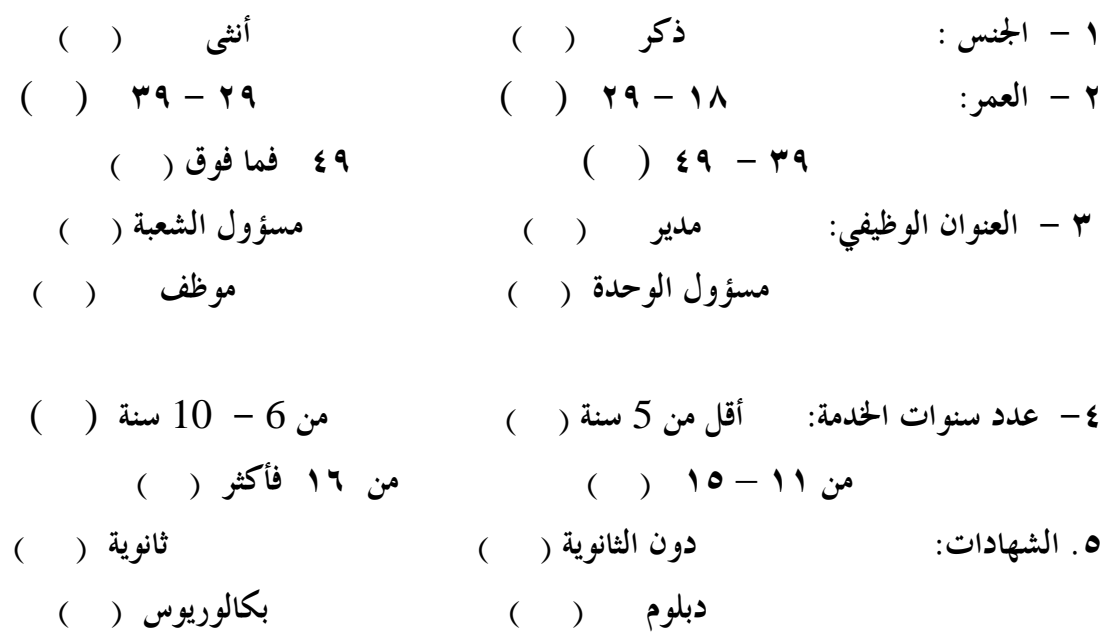

ثانيا: الحدمات المصرفية (X6):

\begin{tabular}{|c|c|c|c|c|c|c|}
\hline لا باتقة & لا اتفق & محايد & اتفق & بشدق & العبارات & الرقم \\
\hline & & & & & 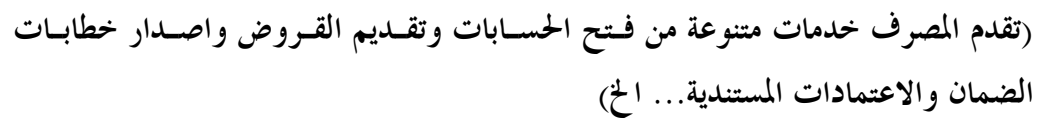 & P1 \\
\hline & & & & & في الجخال الإلكتزوني. & $\mathbf{P 2}$ \\
\hline & & & & & 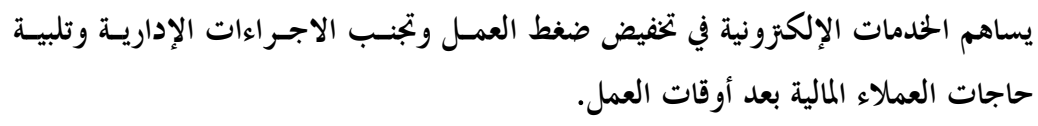 & P3 \\
\hline & & & & & تعمل المصرف على توفير خدمات الصراف الالي داخل الخحافظة.. & P4 \\
\hline & & & & & 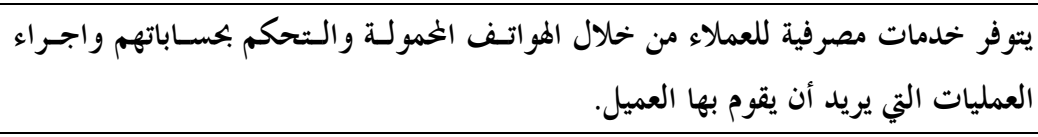 & P5 \\
\hline & & & & & 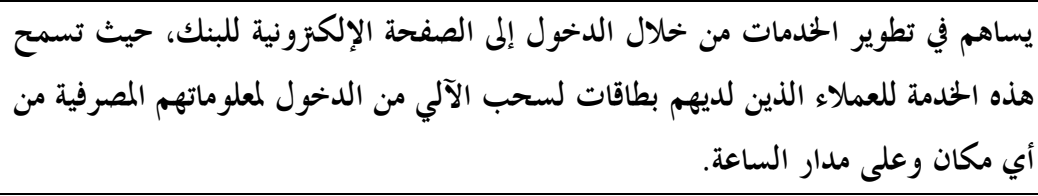 & P6 \\
\hline
\end{tabular}




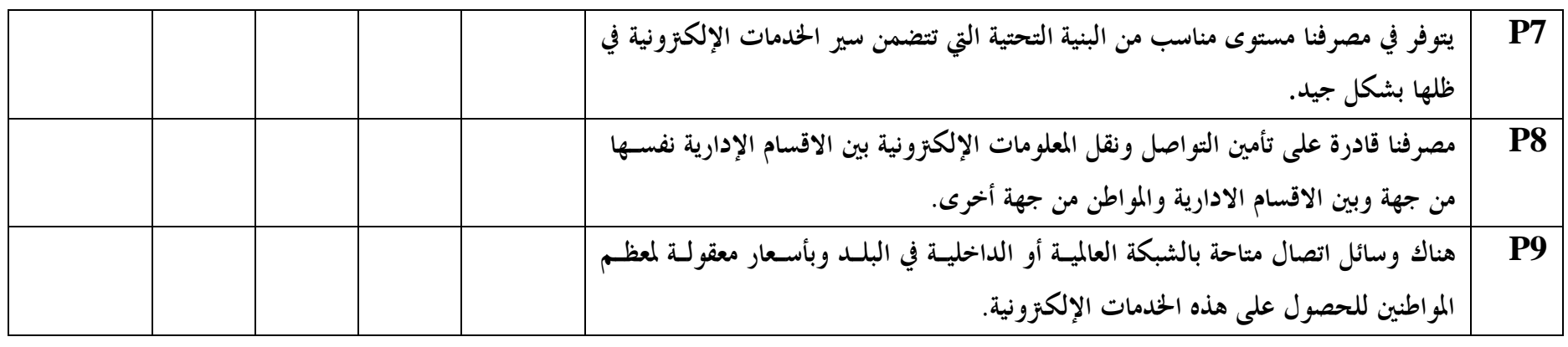

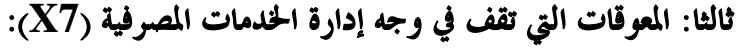

\begin{tabular}{|c|c|c|c|c|c|c|}
\hline لا بشدة & لا لا اتفق & محايد & اتفق & بشقة & 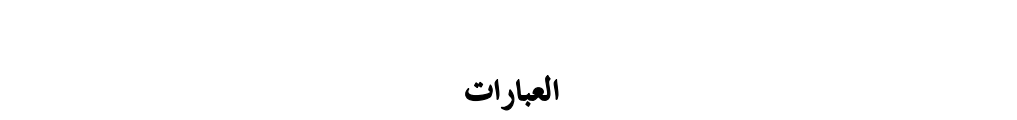 & 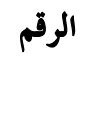 \\
\hline \multicolumn{7}{|c|}{ التحديات الإدارية والتنظيمية X8 } \\
\hline & & & & & هناك ضعف في التكييف مع الأسلوب الإلكزوني الجديد. & $\mathbf{P 1 0}$ \\
\hline & & & & & 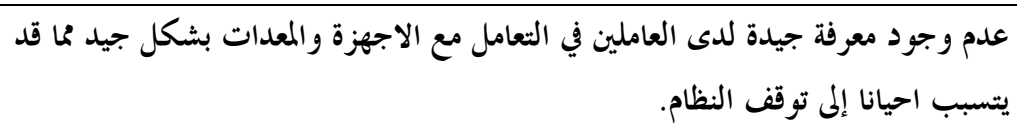 & P11 \\
\hline \multicolumn{7}{|c|}{ التحديات الأمنية (X9) } \\
\hline & & & & & 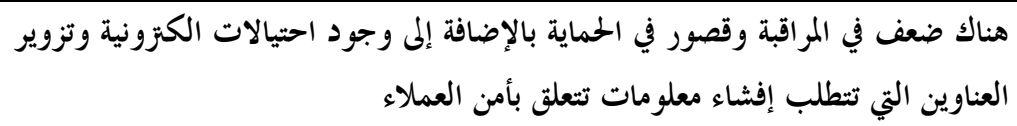 & P12 \\
\hline \multicolumn{7}{|c|}{ التحديات التقنية واستخدامها (X10) } \\
\hline & & & & & والتغطية الإلكزوونية) الحصول المصرف على الأجهزة الحاسوبية المثقدمـة وضسعف شـبكات الاتصـال & P13 \\
\hline & & & & & ( الحدمات المصرفية المطلوبة. من التعامل مع هذا الأسلوب وذلك بسبب عدم ثقتهم به للحصول على & P14 \\
\hline \multicolumn{7}{|c|}{ التحديات القانونية والتشريعية (X11) } \\
\hline & & & & & 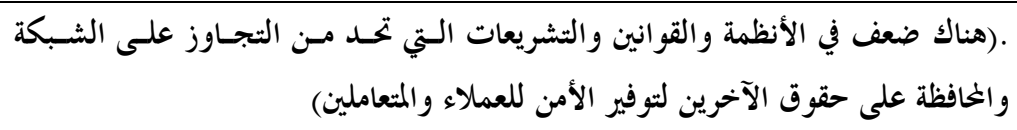 & $\mathbf{P 1 5}$ \\
\hline \multicolumn{7}{|c|}{ التحديات التمويلية (X12) } \\
\hline & & & & & المخرف التقاض التخصيصات المالية للتحول نحو استخدام الحخدمات الإلكتزونية، حيث يحتاج & P16 \\
\hline \multicolumn{7}{|c|}{ التحديات الثنافسية (X13) } \\
\hline & & & & & هناك فرصة كبيرة للمنافسة عن طريق الاتمتة من خلال خلق خدمة واسعة من الحخدمات & P17 \\
\hline & & & & & المعواردالبشر المنافسة مع المصارف الدولية وذلك لعدم توفر الكفاءات المناسبة من & P18 \\
\hline
\end{tabular}

